\title{
Ensayos de consolidación en los revestimientos murales del Conjunto Arqueológico de Castulo (Linares, Jaén)
}

\author{
Ana Isabel Calero-Castillo, Teresa López-Martínez, Ana García-Bueno, María Teresa González-Muñoz, \\ Victor J. Medina-Flórez
}

\begin{abstract}
Resumen: Los revestimientos murales de origen arqueológico presentan una problemática de conservación e intervención muy compleja, en los que la elección del consolidante a emplear ocupa un papel fundamental. Este trabajo pretende mostrar los ensayos de distintos tratamientos de consolidación que se han efectuado sobre fragmentos de pintura mural y de cornisa de cronología romana, procedentes del Conjunto Arqueológico de Castulo. El trabajo ha permitido desarrollar un análisis comparativo entre los distintos tratamientos basándonos, entre otros, en el estudio de micromuestras mediante microscopía electrónica de barrido de alta resolución (HRSEM), permitiendo comprobar las ventajas e inconvenientes del uso de cada uno de ellos.
\end{abstract}

Palabras clave: consolidación, revestimientos murales arqueológicos, Paraloid ${ }^{\circledR}$ B-72, silicato de etilo, carbonatogénesis bacteriana, HRSEM

\section{Consolidations test in the decorative surfaces of the archaeological site of Castulo (Linares, Jaén)}

Abstract: The architectural decorations of archaelogical origin pose a challenge for the conservation and intervention of restauration, in which the choise of the consolidant product plays a key role. This work aims to compare different treatments of consolidation that have been tested on fragments of wall painting and ledge roman from the archaelogical site of Castulo (Spain). This comparative analysis of the different treatments based on, among other techniques, the study of microsamples by scanning electron microscopy of high resolution (HRSEM) allowed to stand out the advantages and disadvantages of using each consolidant product.

Keyword: consolidation, archaeological decorative surfaces, Paraloid B-72, ethyl silicate, biomineralization, HRSEM.

\section{Ensaios de consolidação dos revestimentos murais do Conjunto Arqueológico de Castulo (Linares, Jaén )}

Resumo: Os revestimentos murais de origem arqueológica apresentam uma problemática de conservação e de intervenção muito complexa, onde a escolha do produto solidificador a usar ocupa um papel fundamental. Este trabalho pretende mostrar os ensaios de diferentes tratamentos de consolidação efectuados em fragmentos de pintura mural e de parapeitos romanos procedentes do Conjunto Arqueológico de Castulo. Este trabalho permitiu desenvolver uma análise comparativa entre os diferentes tratamentos, baseando-nos,entre outros, no estudo de micro amostras através da microscopia eletrónica de alta resolução (HRSEM), permitindo comprovar as vantagens e desvantagens da utilização de cada um destes tratamentos.

Palavras-chave: Consolidação, revestimentos de murais arqueológicos, Paraloid ${ }^{\circledR}$ B-72, silicato de etilo, biomineralização, HRSEM 


\section{Introducción}

La problemática de conservación e intervención del material arqueológico radica, principalmente, en dos aspectos.

En primer lugar, extraer la obra a la superficie supone la ruptura del equilibrio establecido entre ésta y el ambiente que la rodea. En el momento de la excavación, habitualmente la obra pasa de estar en unas condiciones de humedad y temperatura que se han mantenido estables durante cientos de años, a ser expuesta a unos valores completamente distintos, pudiendo desencadenar una serie de alteraciones que, unidas a las que ya presentaba antes de su descubrimiento, en ocasiones dificultan su legibilidad y comprensión.

En segundo lugar, la obra de procedencia arqueológica presenta otro problema derivado de las intervenciones que, a menudo, hay que llevar a cabo en el propio yacimiento. En estos casos, tanto las condiciones como los recursos de los que se disponen suelen ser limitados, ocasionando que no sean del todo adecuados e interfiriendo en su posterior intervención, ya sea in situ o en el taller de restauración. Todo ello no supone que no haya que hacerlos, al contrario, puesto que de ellos depende en gran medida la conservación de la obra y su posible manipulación, pero sí la preocupación por elegir el tratamiento más adecuado y compatible, tanto con la obra original como con futuros tratamientos.

En este aspecto, uno de los procedimientos que más inconvenientes presenta, tanto en las intervenciones de urgencia como en los tratamientos definitivos, es la consolidación. Los tratamientos empleados habitualmente generan considerables problemas que se deberían evitar en todo momento, sobre todo por la pérdida de permeabilidad de la capa polícroma, por el cambio que ocasionan en su apariencia y propiedades ópticas, variando parámetros como el brillo, el color, la opacidad o la textura de la capa pictórica, así como por su irreversibilidad con el paso del tiempo (AA.VV. 2003: 19). Todas estas cuestiones exigen tener en cuenta numerosos factores, no solo la elección del consolidante, sino también su método de aplicación e, incluso, las características del disolvente empleado. Del mismo modo, es imprescindible que cumpla uno de los requisitos indispensables para que un material pueda ser utilizado en restauración, su reversibilidad y la compatibilidad con otros posibles tratamientos de restauración como la limpieza, que posteriormente en la mayor parte de los casos deben llevarse a cabo en el taller de restauración.

Resulta por ello primordial la realización de este tipo de estudios, donde analizar con detenimiento las propiedades y el efecto de estos materiales sobre la obra. Además hay que señalar que uno de los problemas fundamentales al abordar este tipo de investigaciones es el gran número de productos de tratamiento que se comercializan para este tipo de superficies y sobre los que, en ciertos casos, hay una limitada experiencia en cuanto a los resultados que proporcionan sobre determinado tipo de obras. Teniendo en cuenta estas consideraciones, y después de hacer una revisión en profundidad de los posibles consolidantes a utilizar, para esta investigación se seleccionaron tres consolidantes entre los que se encuentran dos tratamientos que se han utilizado tradicionalmente para la intervención de este tipo de obras así como uno de nueva incorporación, menos estudiado. En el primer caso, se seleccionaron dos de los consolidantes más empleados en contextos arqueológicos (ya sea para tratar los revestimientos antes de su extracción, para su conservación in situ o en el museo) que son la resina acrílica de metacrilato-etilmetacrilato, más conocido como Paraloid ${ }^{\circledR}$ B72 y el silicato de etilo (Bioestel 1200-CTS) (Moreno Cifuentes 1998:66; Renzo dal Monte 1998:113). Por otra parte se ha seleccionado el tratamiento de bioconsolidación por carbonatogénesis bacteriana, un tratamiento de reciente incorporación cuya investigación se ha centrado básicamente en su empleo sobre piedra, pero sobre el que en los últimos años se está investigando para este tipo de revestimientos con acabados polícromos (Jroundi et al. 2014: 3844-3854).

De manera que, en este caso concreto se pretende, a partir del análisis comparativo de los distintos tratamientos aplicados sobre fragmentos de pintura mural y de cornisa procedentes de la Sala del Mosaico de los Amores del Conjunto Arqueológico de Castulo [figura 1], establecer las ventajas e inconvenientes del empleo de cada uno de ellos, estudiando en cada caso los cambios que se producen en la morfología original de la obra y la distribución del consolidante, valorando la respuesta del mismo tratamiento sobre dos materiales similares pero ejecutados siguiendo técnicas distintas ya que, si bien tanto la pintura mural como la cornisa están compuestas por morteros de cal, mientras que la primera de ellas se presenta espatulada y conserva la capa pictórica en su totalidad, en el caso de la cornisa, el mortero resulta mucho más poroso y solo conserva restos puntuales de policromía.

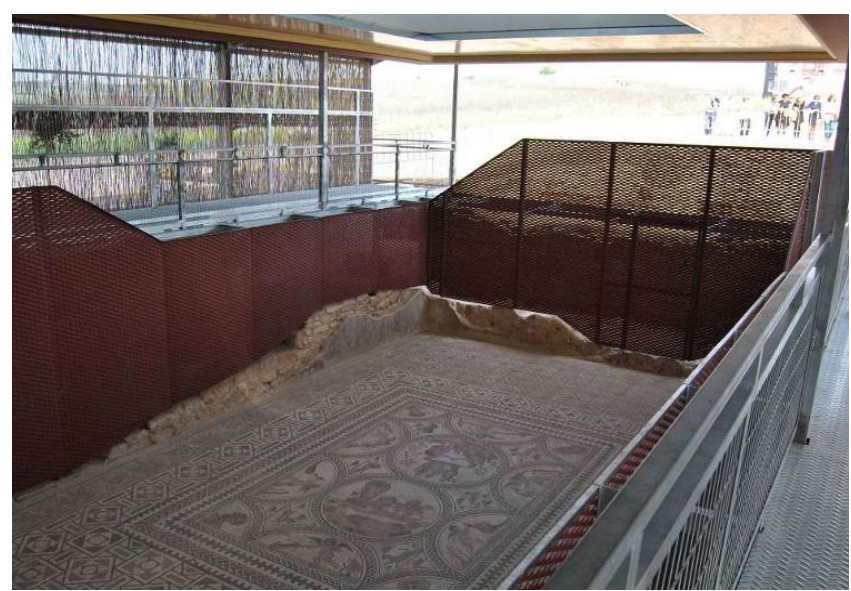

Figura 1.- Sala del Mosaico de los Amores del Conjunto Arqueológico de Castulo. 


\section{Objetivos}

El objetivo principal de esta investigación se centra en uno de los aspectos fundamentales a evaluar en los tratamientos de consolidación: valorar la compatibilidad entre los consolidantes y los materiales constitutivos de la obra. El concepto de compatibilidad se refiere a que el consolidante tenga una naturaleza y propiedades similares al material original de modo que no cambie sustancialmente las características de éste $y$, por tanto, actúe como un solo material, no dando lugar a tensiones internas ni a una velocidad de degradación diferente. En este último sentido no es necesario que sean iguales que el material original, pero deben resistir las modificaciones del sustrato y del ambiente. Además se debe tener en cuenta uno de los principios fundamentales de Cesare Brandi con el que se acepta que la intervención realizada no será, seguramente, la última, por lo que debe permitir tratamientos posteriores (López Ortega 1999). No hay que olvidar que cualquier material que se introduzca en la obra va a modificar su relación con el ambiente, de manera que su comportamiento en el futuro puede verse afectado. Cuando se interviene un revestimiento de estas características el objetivo es conseguir su conservación y que su comportamiento mejore, es decir, que disminuya su alterabilidad.

Teniendo en cuenta estas consideraciones, y la ya expuesta problemática de conservación e intervención que presentan los revestimientos arqueológicos, sobre todo en cuanto a tratamientos de consolidación se refiere, con este estudio se han perseguido fundamentalmente los siguientes objetivos:

- Realizar una revisión de los posibles tratamientos de consolidación a emplear en revestimientos murales de procedencia arqueológica y seleccionar aquellos que puedan considerarse más adecuados y compatibles.

- Hacer pruebas sobre fragmentos descontextualizados para analizar la penetración de cada tratamiento y el cambio que produce en la morfología original de la obra.

- Valorar la respuesta que ofrece cada tratamiento en función de la técnica de ejecución que presenta el revestimiento mural, manteniendo el mismo material.

- Desarrollar nuevas líneas de investigación encaminadas a la puesta a punto de nuevos materiales y procedimientos de restauración aplicables a obras de tipología similar.

\section{Metodología}

En un trabajo de este tipo resulta imprescindible la aplicación de una metodología rigurosa, de forma que se puedan establecer conclusiones seguras y fiables. En este caso, se ha buscado que el material sobre el que se ensayasen los distintos métodos de consolidación se asemejasen al máximo a las características originales, de manera que se pudiera comprobar la respuesta específica del tratamiento sobre la obra original. Es por ello que las pruebas se han realizado sobre pequeños fragmentos descontextualizados pertenecientes a los revestimientos murales de la Sala del Mosaico de los Amores, en el Conjunto Arqueológico de Castulo, concretamente proceden de los paneles intermedios de la composición de la decoración parietal y de la zona superior, correspondiente a una cornisa decorada con motivos vegetales. Para ello se ha seguido la siguiente metodología:

\section{-Elección de los fragmentos:}

Escoger fragmentos tanto de pintura mural como de cornisa permite estudiar el comportamiento de cada tratamiento sobre revestimientos que, presentando los mismos materiales constitutivos, difieren en la técnica de ejecución. Por un lado, la pintura mural está ejecutada al fresco sobre mortero de cal y siguiendo la técnica de las politiones, es decir, el pulido de la superficie por el que se facilita la salida del agua y el hidróxido cálcico que queda en el interior del mortero favoreciendo nuevas carbonataciones en la superficie y compactando en gran medida el mortero (Mora et al. 2002: 115-118). Los fragmentos escogidos son todos de color rojo, ya que éste es el color que se presenta en mayor proporción en la decoración de la estancia, además de ser el que mayores problemas de conservación posee, mostrándose muy pulverulento. Por otro lado, en la cornisa que está realizada con un mortero de cal con otros materiales en pequeña proporción, se percibe una base mucho más porosa. En este caso la policromía que conserva es muy escasa, también de color rojo y, en algunas zonas, amarillo.

En ambos casos se ha tomado la precaución de emplear fragmentos hallados en las cribas de tierra de forma que no hubiesen recibido ningún tratamiento previo en el momento de la extracción de los fragmentos, y fuese posible el análisis de cada consolidante sobre el material original, sin ningún tipo de interferencia [figura 2].

Los fragmentos seleccionados se trasladaron a uno de los laboratorios del Centro de Restauración de la Universidad de Granada donde se llevó a cabo la aplicación de los diferentes tratamientos.

\section{—Elección de los tratamientos consolidantes:}

Como ya se ha señalado, dentro de las intervenciones que se realizan en las excavaciones, la consolidación es una de las que más complejidad plantea, ya que debe de adecuarse a la problemática de su aplicación in situ, además de permitir la posterior intervención de la obra (limpiezas, consolidaciones posteriores). Como se ha expuesto en 


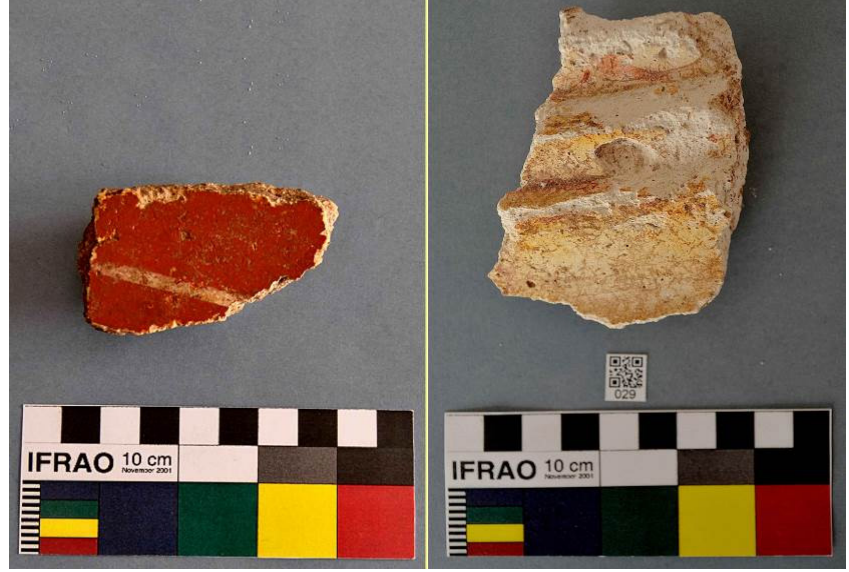

Figura 2.- Fragmento de pintura mural y de cornisa empleados para el estudio.

la introducción, se decidió escoger para estos ensayos dos de los tratamientos más empleados en arqueología, como son el Paraloid $^{\circledR}$ B-72 y el Bioestel 1200. El Paraloid ${ }^{\circledR}$ B-72, es el consolidante orgánico más empleado en el campo de la restauración y está constituido por una resina acrílica al $100 \%$ cuya composición está formada por un copolímero de metilacrilato y etilmetacrilato. En el segundo caso, el Bioestel 1200 es un éster de silicio, cuya acción se basa en la precipitación de la sílice en el interior de los poros que incorpora además en este caso una "acción protectora de la degradación producida por la contaminación y el desarrollo de organismos vegetales biodeteriorantes" (Dal Monte 1998:113).

De forma general, la ventaja de la resina acrílica radica en su reversibilidad, aunque puede crear una barrera impermeable sobre la capa pictórica que, en ese caso, ocasionaría graves problemas; por otra parte, el cambio que ocasiona en la porosidad del material dificulta los procesos de secado del muro, pudiendo generar problemas de cristalización de sales. Por el contrario, la ventaja del silicato de etilo reside en la afinidad de su composición con los materiales constitutivos de la obra, aunque por el contrario, su reversibilidad es peor.

Dado que ambos materiales, en ocasiones, plantean problemas, el primero por crear una capa prácticamente impermeable y el segundo por su irreversibilidad, se optó por seleccionar un material experimental que hasta el momento ha demostrado resultados bastante satisfactorios en la consolidación de material pétreo, la carbonatogénesis bacteriana, y que a priori presenta ventajas como respetar la permeabilidad de los materiales sobre los que se aplica y no interferir en tratamientos posteriores (González-Muñoz et al. 2015; Jroundi et al. 2011). Su acción se basa fundamentalmente en la formación de minerales mediante un proceso biológico a partir de la aplicación de una solución nutritiva adecuada que activa las bacterias carbonatogénicas presentes en los revestimientos, induciendo a la precipitación de carbonato cálcico natural como consecuencia de su metabolismo, lo que produce la consolidación del substrato. Esto es debido al hecho de que la producción de carbonato cálcico por bacterias es un fenómeno bastante extendido (Boquet et al. 1974) y de que se ha encontrado que práctimante el $95 \%$ de las bacterias presentes en el patrimonio pétreo son carbonatogénicas (Jroundi et al. 2010; Rodríguez-Navarro et al., 2015:89-92); igualmente, su actividad se ha detectado en revocos de yeso (Jroundi et al. 2014), comprobándose la eficacia de este tratamiento en estudios anteriores sobre yesos de procedencia arqueológica (Jroundi et al. 2014; Jroundi et al. 2011) en los que se ha puesto de manifiesto "una adecuada activación de las bacterias carbonatogénicas y consiguientemente, un notable grado de consolidación" (González-Muñoz et al. 2015:97). Sin embargo, ya que los ensayos que hasta el momento se han realizado son sobre material pétreo o morteros de yeso con escasísimos restos de policromía, en este trabajo se pretende valorar el nivel de consolidación real que presenta sobre capas pictóricas.

En lo que respecta a los materiales utilizados mientras que los dos primeros fueron adquiridos de la casa comercial CTS, la solución nutritiva M3-P necesaria para la aplicación del tratamiento de la carbonatogénesis bacteriana nos fue facilitada por el Departamento de Microbiología de la Facultad de Ciencias de la Universidad de Granada, responsables de la patente de este producto (GonzálezMuñoz et al. 2008) que se encuentra comercializado por la compañía global biotecnológica KBYO Biological SL.

\section{- Aplicación de los tratamientos:}

Todos los fragmentos, tanto los de pintura mural como los de cornisa, han sido tratados en una primera fase de la misma manera: tras una documentación fotográfica del estado inicial, se ha realizado una limpieza mecánica eliminando restos de depósitos terrosos y concreciones y se ha procedido a la aplicación de los diferentes tratamientos de consolidación.

En el caso del silicato de etilo y de la resina acrílica, se ha seguido la misma metodología variando sólo su concentración; el primero de ellos se ha aplicado sin diluir mientras que la consolidación con Paraloid ${ }^{\circledR}$ B-72 se ha realizado en disolución al 5\%. Para ello, en vez de utilizar un disolvente orgánico como el tolueno o el disolvente nitrocelulósico, se ha realizado una mezcla de tres disolventes menos tóxicos bajo una fórmula ideada por los profesores del ISCR (Istituto Superiore per la Conservazione ed il Restauro) de Roma, Maurizio Coladonato y Fabio Talarico; en concreto, se ha empleado Taco 8, disolvente de volatilidad media compuesto por alcohol isopropílico, octano y acetona, a una concentración del 45\%, 32\% y $23 \%$ respectivamente. Además de la menor toxicidad, esta mezcla de disolventes tiene una velocidad de evaporación menor, lo que impide, en gran medida, que se cree una película superficial. 
En ambos casos, la aplicación del tratamiento se ha llevado a cabo mediante pincel de pelo suave, protegiendo la capa pictórica con papel japonés y se ha repetido el proceso una vez al día durante tres días consecutivos. Por el contrario, el tratamiento con carbonatogénesis bacteriana exige una metodología diversa que ha consistido en la aplicación mediante nebulización de la solución nutritiva acuosa M-3P sobre la superficie pictórica hasta saturación, realizando tres aplicaciones al día durante seis días consecutivos desde, aproximadamente, $20 \mathrm{~cm}$ de distancia, según la técnica descrita por Jroundi et al. (2014). En los tres casos se estableció un tiempo de curado de tres meses.

\section{-Métodos de análisis:}

Una vez realizados los tratamientos se han valorado sus resultados con métodos objetivos, estudiando tanto los cambios estructurales producidos en la materia, como los cambios estéticos de la capa pictórica. Para ello se ha realizado un análisis visual de la superficie, pruebas de solubilidad en el caso de los fragmentos de pintura mural y un análisis textural y elemental mediante microscopía electrónica de barrido de alta resolución (HRSEM).

Cabe señalar que previamente a estos ensayos se analizaron diversas muestras con el fin de caracterizar los materiales constitutivos de los revestimientos murales (López Martínez et al. 2016). Gracias a las diversas técnicas empleadas (microscopía estereoscópica, microscopía petrográfica, microscopía electrónica de barrido con EDX, difracción de rayos $X$, cromatografía de gases y espectroscopía infrarroja por transformada de Fourier) ha sido posible reconocer, en el caso de la pintura mural, cuatro estratos de mortero de cal y árido a base de cuarzo, feldespato potásico y plagioclasas, en una proporción del $75 \%$ de árido en el estrato más superficial, y una capa pictórica constituida por hematites y minio [figura 3]. En el caso de la cornisa, se ha identificado un mortero de cal con porcentajes minoritarios de sulfato de calcio y de silicio y, en casos puntuales correspondientes a las zonas policromadas, hierro.

Para el análisis de los ensayos de consolidación, se han tomado, en primer lugar, micromuestras de todos los fragmentos y se han analizado mediante microscopio estereoscópico; se ha utilizado un microscopio Nikon SMZ 1000 del que se obtuvieron microfotografías tanto de la superficie como del corte estratigráfico gracias a la cámara que lleva incorporada el dispositivo (DS-U3 Digital Camera). Para ello, las micromuestras se prepararon dividiendo cada una de ellas en dos mitades y colocando ambos fragmentos en un mismo soporte, uno en posición horizontal y otro en posición vertical, de forma que se pudiese analizar tanto la capa pictórica como el perfil del corte [figura 4]; en todo momento las muestras se han manipulado con pinzas buscando la sección sobre la cual se obtiene mayor información. La realización de las microfotografías antes de ser metalizadas las muestras

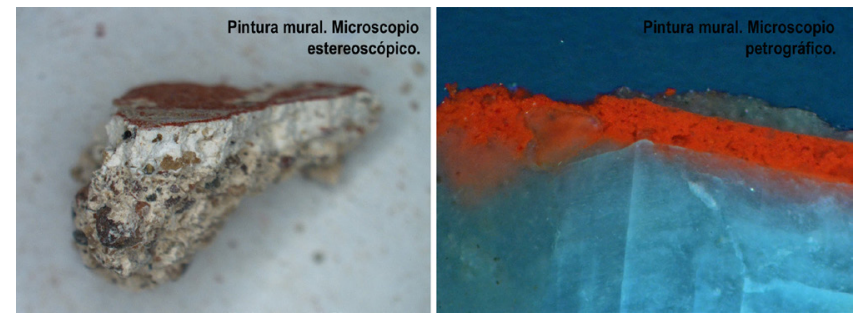

Figura 3.- Muestras estudiadas mediante microscopio estereoscópico y microscopio petrográfico.

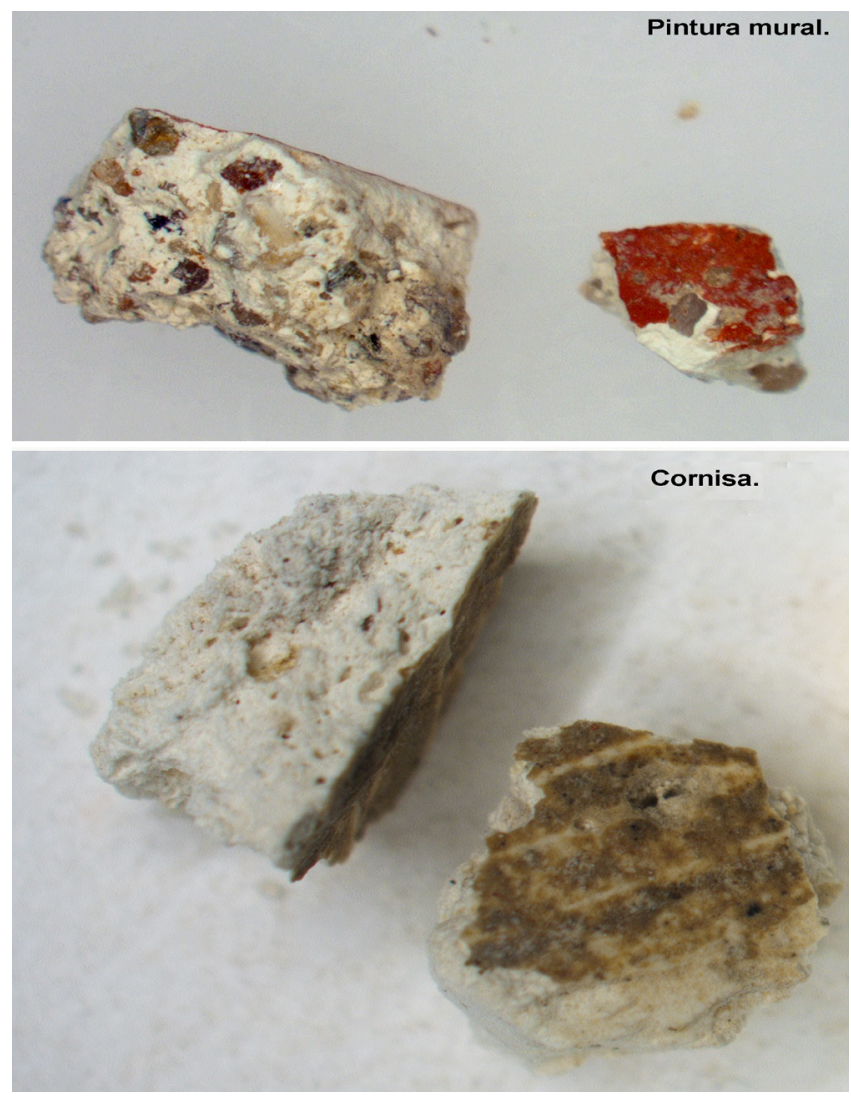

Figura 4.- Esta figura es identificativa de la metodología de estudio tanto de pintura mural como de cornisa. En ambos casos, como se especifica en el texto se seleccionó un fragmento para el estudio del perfil y otro para el estudio de la superficie como puede comprobarse en esta figura.

con carbono supone una gran ventaja ya que permite referenciar las características estéticas de cada muestra $y$, en caso de querer obtener información sobre algún aspecto en concreto o realizar alguna aclaración, poder recurrir a las imágenes. Con esta observación se ha podido examinar la estratigrafía, restos de policromía, morfología del mortero y cambios de apariencia entre los diferentes fragmentos tratados.

Tras el análisis con microscopio estereoscópico se han metalizado las muestras y se ha procedido a su estudio mediante microscopía electrónica de barrido de presión variable de alta resolución (HRSEM), para lo que se ha empleado un microscopio electrónico de barrido de presión variable de alta resolución Zeiss SUPRA 40VP 
equipado con sistema de microanálisis por Energía dispersiva de Rayos X (EDX) con detector de gran superficie X-Max 50mm. El objetivo fundamental de este método ha sido obtener datos precisos de la distribución de los consolidantes sobre las muestras tratadas, tanto en superficie como en profundidad, detectar diferencias entre las muestras consolidadas y sin consolidar (porosidad, cambios de composición, sistema de cristalización, grado de penetración del consolidante...), así como posibles alteraciones o particularidades de los tratamientos tales como la morfología de la película que forman y sus características. Para ello, se ha establecido una metodología de estudio que se ha seguido en todas las muestras analizadas. Esta sistemática ha consistido en la obtención de imágenes de diferentes resoluciones de la superficie de las muestras estudiadas (100x, 500x, 1500x, 5000x, 15000x), mapas de distribución de elementos de la superficie (bajo las siguientes condiciones: mapa de 510 pixeles, binning factor, imagen con resolución de 1024 pixeles, 34 frames, $20 \mathrm{kw}, 100$ microsegundos, 13,6 duel time) así como un análisis elemental de la distribución del consolidante en el perfil (line profile) que ha sido determinante para observar la penetración de los tratamientos y su composición.

Finalmente, las pruebas de solubilidad realizadas en los fragmentos de pintura mural se han llevado a cabo mediante la doble rotación de un hisopo impregnado de agua destilada sobre la capa pictórica.

\section{Resultados}

En primer lugar, el examen a visu no ha mostrado cambios evidentes entre la superficie sin tratar y la superficie una vez tratada. Tanto en el caso de los fragmentos de pintura mural como en los fragmentos de cornisa, el color de la policromía no se ha visto modificado con ningún tratamiento ni tampoco se aprecian cambios estructurales significativos en la superficie de los fragmentos.
En el caso de las pruebas de solubilidad realizadas a los fragmentos de pintura mural se ha comprobado que, mientras que antes de los tratamientos de consolidación la capa pictórica se mostraba pulverulenta y se dispersaba al menor contacto con el agua, tras la aplicación de los tratamientos la capa se muestra más cohesionada, no manchando de color el hisopo impregnado de agua destilada cuando éste se rotaba sobre la superficie.

Por el contrario, el análisis con HRSEM ha puesto en evidencia las diferencias entre los tratamientos que en el examen $a$ visu eran imposibles de apreciar. En lo que respecta al comportamiento de los tratamientos en ambos revestimientos (pintura mural y cornisa) los resultados han sido fundamentalmente los mismos con pequeñas diferencias que se detallarán en la exposición de los resultados.

En primer lugar se ha estudiado una muestra sin tratar tanto de pintura mural como de cornisa, de forma que sirviese de testigo comparativo para analizar las modificaciones que se pudieran producir tras la aplicación de los diversos consolidantes. En lo que respecta a la morfología del mortero, la observación realizada mediante HRSEM ha permitido constatar que la diferencia de ejecución entre ambos revestimientos ha dado lugar a cambios en el aspecto textural de ambos. Mientras que en los fragmentos de pintura mural observamos un mortero compacto, consecuencia del espatulado, en el caso de los fragmentos de cornisa se percibe un mortero mucho más poroso, lo que se debe tanto a la técnica de ejecución (molde o terraja de madera) como a la posible adición de material orgánico en la formulación del mortero (aunque no se haya podido detectar en los análisis) para aligerar el peso de estos revestimientos que se encontraban en la parte superior de los muros tal y como era habitual en la realización de este tipo de decoraciones (Guiral Pelegrin y Martín-Bueno 1996) [figura 5].

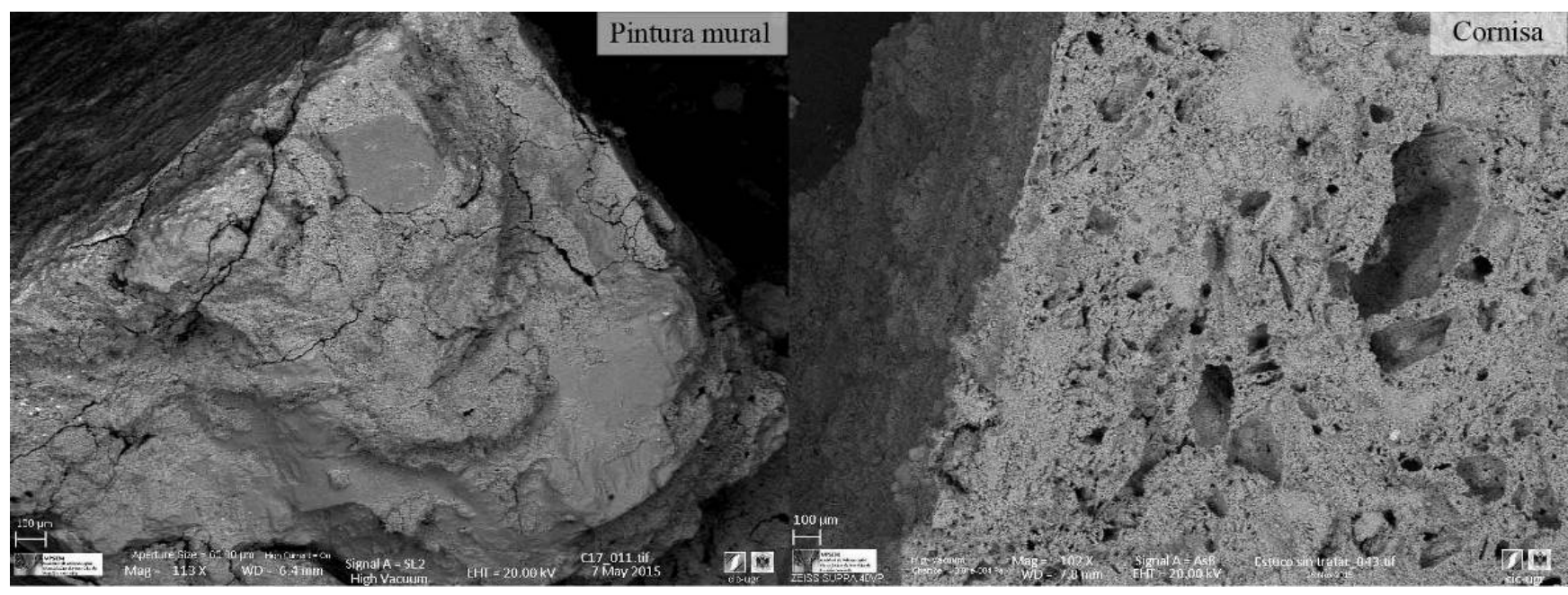

Figura 5.-Diferencias entre las texturas del mortero procedente de pintura mural y el de cornisa. Imagen obtenida mediante HRSEM. 
En lo que respecta a los resultados obtenidos en el análisis de los fragmentos tratados, la mayor información se ha conseguido a partir del estudio de la morfología de la muestra. En el caso de los tratamientos con resina acrílica y silicato de etilo, los datos obtenidos del análisis del line profile han corroborado la información recopilada al observar las imágenes; sin embargo, el tratamiento con carbonatogénesis bacteriana, dado que consolida con el mismo material que constituye el mortero, sólo se ha podido comprobar mediante el examen morfológico de la superficie, ya que resultaba imposible diferenciar el carbonato cálcico de nueva formación respecto al material constitutivo tanto de la superficie como del perfil, no dando resultados concluyentes.

El estudio de las muestras tratadas con silicato de etilo ha permitido observar con claridad tanto en el fragmento tratado de pintura mural como de cornisa, la existencia de una serie de grietas de similar morfología en la superficie [figura 6]. Se ha considerado que estas pequeñas fisuras pudieran deberse a la rigidez de la película que forma este tipo de consolidante en las que al evaporarse el disolvente hubiera provocado su fractura. Este tipo de alteración ya ha sido expuesta en otros trabajos de investigación sobre consolidantes como en el publicado por Jroundi et al. (2014) en el que se realizaron pruebas sobre fragmentos de yeso procedentes del Alcázar de Guadalajara. En lo que respecta a su penetración en el caso de la pintura mural se detecta material hasta aproximadamente $30 \mu \mathrm{m}$, mientras que en la cornisa éste llega hasta aproximadamente $100 \mu \mathrm{m}$, lo que se ha atribuido a su porosidad [figura 7]. Por otra parte, el mapa de distribución de elementos muestra un depósito homogéneo de silicio por toda la superficie tratada [figura 8].

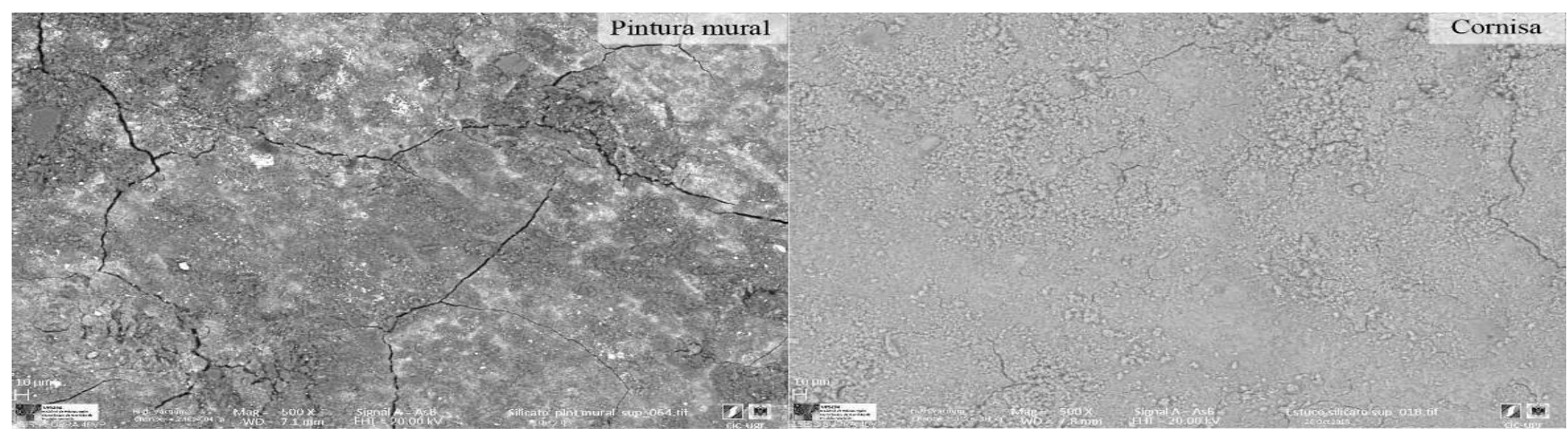

Figura 6.-Diferencias entre las texturas del mortero procedente de pintura mural y el de cornisa. Imagen obtenida mediante HRSEM.

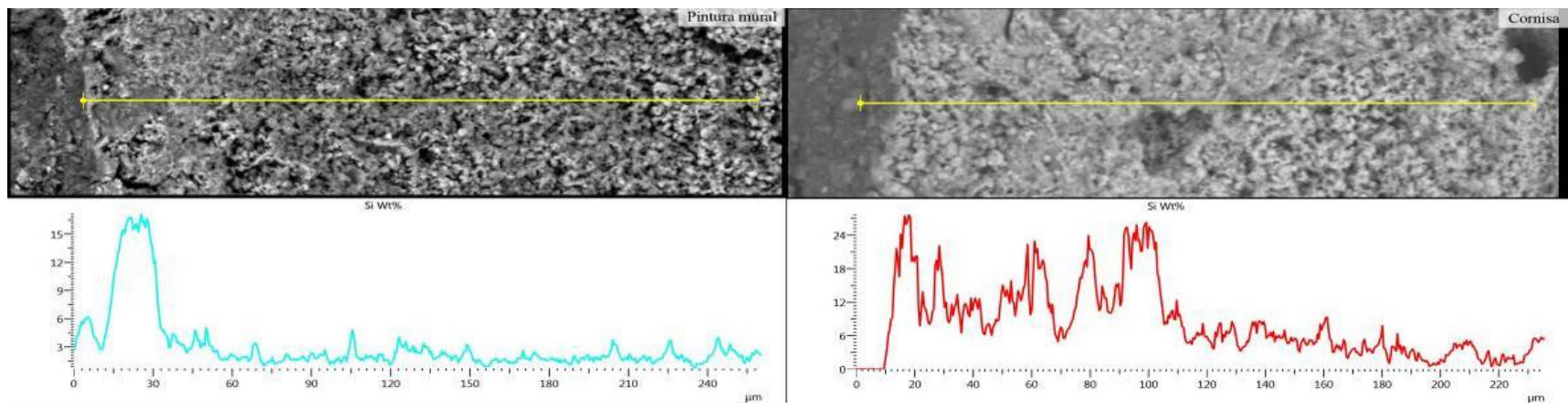

Figura 7-Grado de penetración de las muestras tratadas con silicato de etilo. Line profile del fragmento de pintura mural (izq.) y de la cornisa (derecha) en el que se muestra la cantidad de silicio identificado.

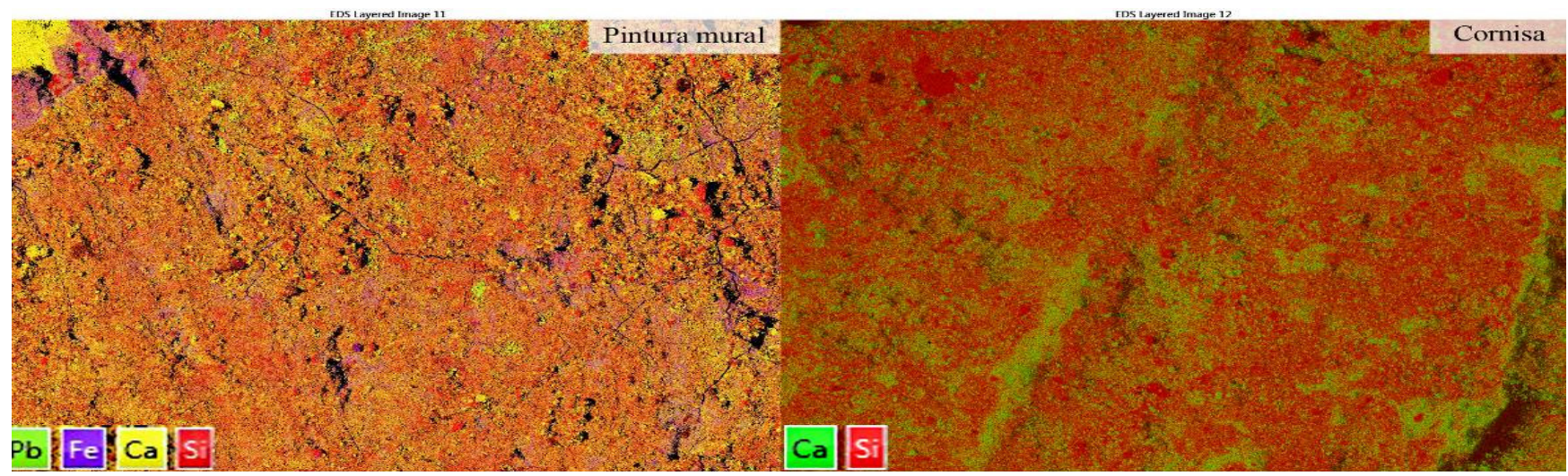

Figura 8-Mapa de distribución de elementos de las muestras tratadas con silicato de etilo. En ambos casos el silicio está representado con color rojo. 
Por otra parte, aparentemente, la consolidación con resina acrílica tanto en el fragmento de pintura mural como en el de cornisa no evidencia cambios significativos ni en el perfil ni en la superficie. Solamente en el caso de la moldura se observan restos en la imagen de perfil de lo que parece ser una película de aspecto plástico [figura 9]. Los resultados obtenidos se han comparado con una investigación que de forma paralela se está llevando a cabo, en la que se aplicó una capa de resina acrílica a mayor concentración a un fragmento de pintura mural tras su extracción para la fijación de su policromía en el mismo yacimiento, lo que ha permitido obtener observaciones bastante interesantes. Si se comparan ambos resultados se advierte que en el caso del fragmento tratado in situ, la capa pictórica evidencia la huella de burbujas creadas por la resina acrílica además de craquelados y desprendimientos, mientras que en el tratado a menor concentración esto no se observa [figura 10]. Por otro lado, atendiendo a la visión del corte en el fragmento tratado en la excavación con la resina acrílica en mayor proporción, se percibe claramente un estrato orgánico superpuesto a la capa pictórica. En todas las muestras tratadas en el yacimiento se observa cómo la resina ha cubierto con un film la superficie por completo, percibiéndose un claro contraste entre la superficie y el interior de la grieta, donde se mantiene la textura original, mientras que en las muestras tanto de pintura mural como de cornisa en las que se aplicó el producto al $5 \%$ en el laboratorio no se detecta la formación de esta película.

En cuanto a lo que respecta del análisis del line profile se observa una penetración relativamente superior a la del silicato de etilo; en el caso del fragmento de pintura mural se caracteriza material orgánico hasta $50 \mu \mathrm{m}$ aproximadamente de profundidad, mientras que en la cornisa la presencia de materia orgánica no muestra una variación significativa [figura 11].

Finalmente, el estudio de la muestra de pintura mural y de la cornisa consolidadas con carbonatogénesis bacteriana ha permitido comprobar que el tratamiento no presenta grietas o fracturas aparentes cuando se realiza un examen general de la muestra (100x). A dicha

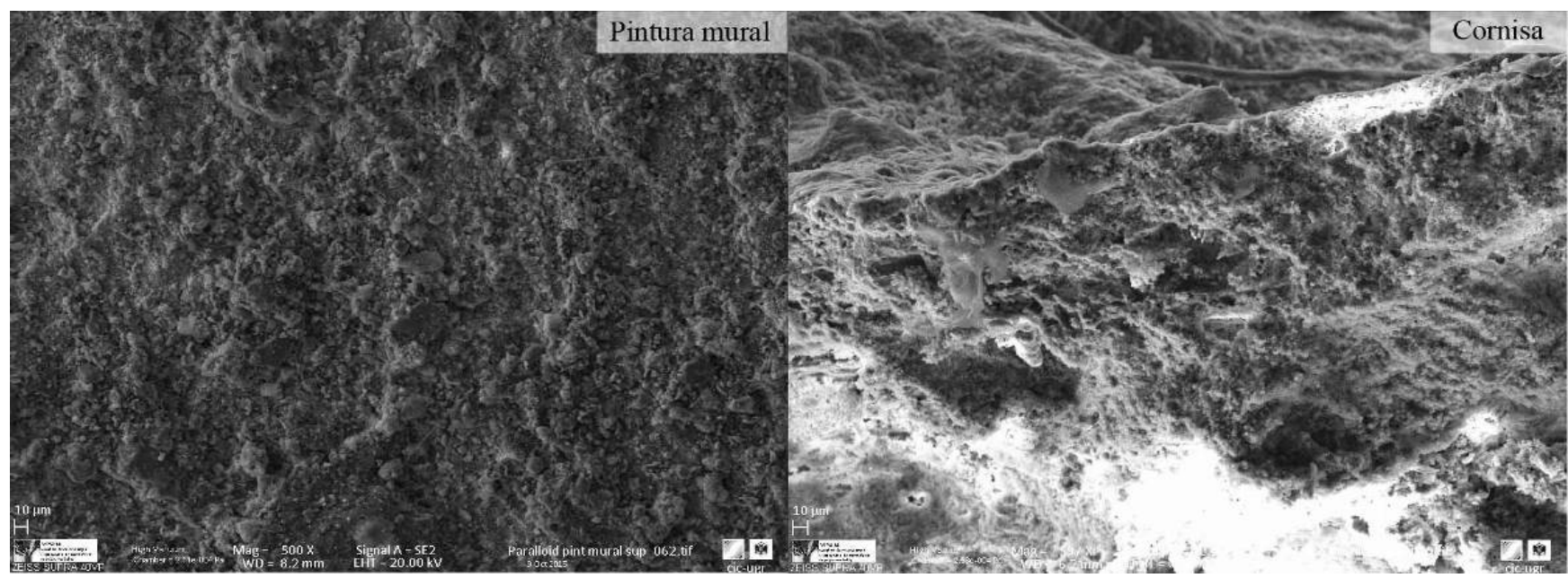

Figura 9- Muestras tratadas con Paraloid B-72 al 5\%. Imágenes obtenidas mediante HRSEM.

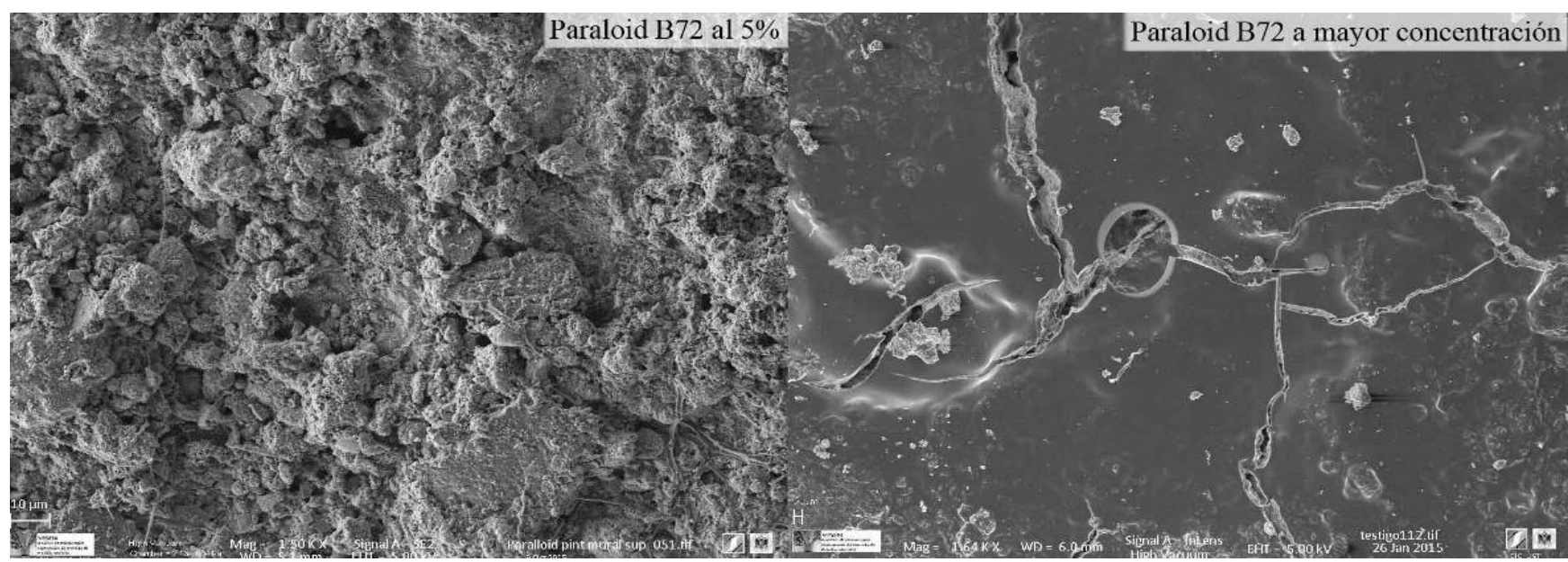

Figura 10- Diferencias entre la muestra tratada con Paraloid B-72 al 5\% (izq.) y la tratada con la misma resina en mayor concentración (derecha). Imágenes obtenidas mediante HRSEM. 

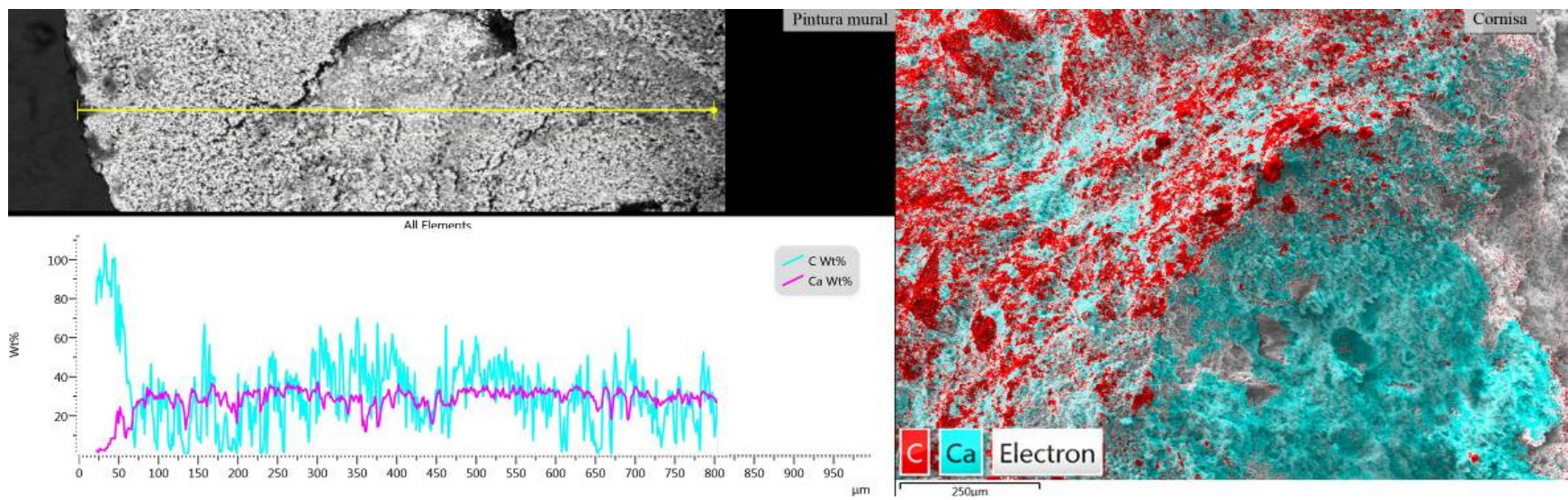

Figura 11-Grado de penetración de las muestras tratadas con Paraloid B-72. Line profile del fragmento de pintura mural (izq.) y mapa de distribución de elementos de la muestra colocada de perfil de cornisa donde puede comprobarse la escasa penetración del producto.

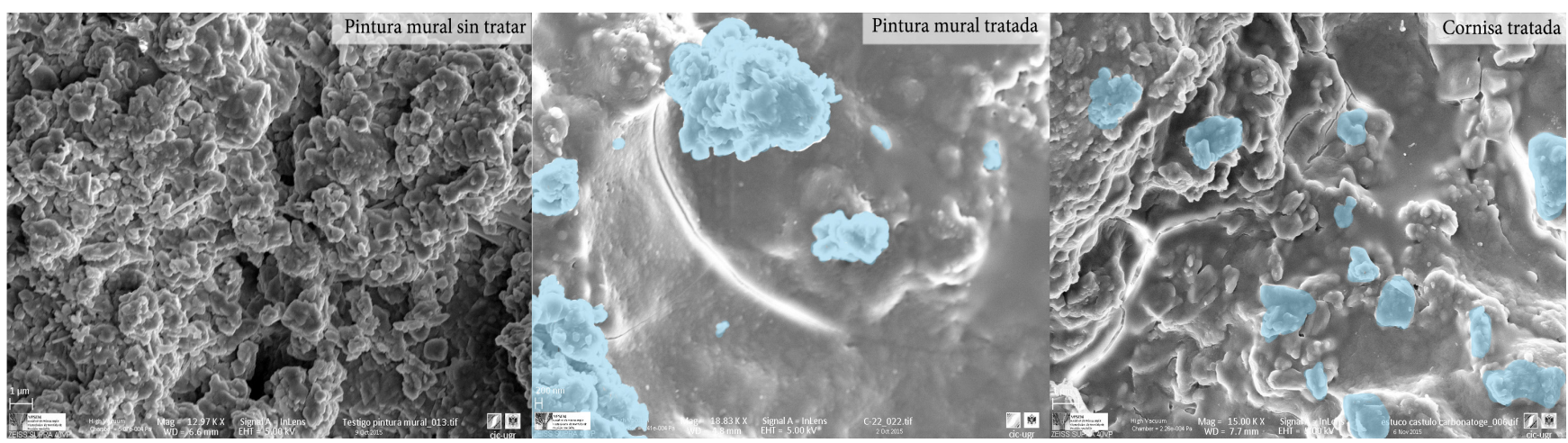

Figura 12- Muestra testigo de pintura mural y muestras tratadas mediante carbonatogénesis bacteriana donde se aprecian las sustancias expoliméricas y la calcita de nueva formación (señaladas en color azul). Imágenes obtenidas mediante HRSEM. Las barras corresponden a $1 \mu \mathrm{m}$ en la microfotografía correspondiente a pintura mural sin tratar, a $200 \mathrm{~nm}$ en la correspondiente a pintura mural tratada y a $1 \mu \mathrm{m}$ en la correspondiente a cornisa tratada.

magnificación puede parecer que el tratamiento ha creado una película sobre la superficie semejante a la que produce la resina acrílica; sin embargo, al elevar los aumentos se puede distinguir que lo que antes parecía una película impermeable es en realidad el tapizado de la superficie provocado por la precipitación de cristales de carbonato cálcico de nueva formación.

Asimismo se pueden apreciar la presencia de sustancias exopoliméricas (EPS), constituidas mayoritariamente por exopolisacáridos y proteínas (Branda et al. 2005) formadas como subproducto de la actividad microbiana y la existencia de fracturas derivadas de la formación del ya citado tapiz que respeta la morfología del fragmento tratado [figura 12]. El tratamiento aplicado conduce a la producción de carbonato cálcico al dar lugar a las condiciones físico-químicas necesarias para la actividad microbiana, además de que tanto las células bacterianas como el EPS que éstas producen actúan como núcleos heterogéneos de cristalización para la producción de carbonato cálcico, por lo que todo el proceso contribuye a la consolidación del material tratado (ver, por ejemplo, Jiménez-Lopez et al. 2008, Rodriguez-Navarro et al. 2015).
Aunque en este caso no se ha podido comprobar la penetración del producto, en investigaciones publicadas realizadas sobre yesos arqueológicos, en los que sí se puede comprobar el aumento de carbonato cálcico y su profundidad, se afirma que alcanza los $2 \mathrm{~cm}$ de profundidad (Jroundi et al. 2014); se puede considerar que en este caso fuera algo similar.

\section{Conclusiones}

Los resultados obtenidos han demostrado la efectividad de los productos ensayados, no obstante se deben tener en cuenta las particularidades que presentan cada uno de ellos con el objetivo de seleccionar el más adecuado atendiendo a las características de la obra tratada. Los datos recopilados de los fragmentos de pintura mural y cornisa son muy parecidos, demostrando que presentan un comportamiento similar, lo que es lógico debido a las coincidencias en su composicion material.

En el caso de la resina acrílica de metacrilato-etilacrilato Paraloid ${ }^{\oplus}$ B-72, tanto el mapa de distribución de 
elementos como el análisis del perfil demuestran una presencia importante de producto y por tanto su efectividad. Sin embargo, se debe tener en consideración, sobre todo cuando la concentración es superior al 5\%, que se produce la formacion de una película densa en superficie, que aunque es indicativa de la efectividad, también lo es de una capa que afecta a la permeabilidad del soporte. Por este motivo, este producto sería recomendable en bajas concentraciones y siempre que la obra se encuentre en condiciones estables y controladas.

En lo que respecta al silicato de etilo, Bioestel 1200, se puede afirmar que presenta una ventaja fundamental que es la de la compatibilidad material. Sin embargo, su escasa penetración (en torno a las $100 \mu \mathrm{m}$ ) y la formación de una película que se microfractura deben tenerse en consideración cuando se aplica sobre este tipo de revestimientos, sobre todo en substratos poco porosos donde el producto tiende a quedar muy en superficie.

Por último, en el caso de la carbonatogénesis, aunque no se produce una capa uniforme como en el resto de los tratamientos, se ha podido constatar la formación de sustancias exopoliméricas, producto de la acción bacteriana que, junto con el carbonato cálcico de nueva formación, han consolidado la superficie. Este hecho se ha considerado muy importante pues es indicativo de que el tratamiento, además de ser efectivo, respeta la porosidad del soporte tratado y no impide tratamientos posteriores, ya que el material formado es el mismo del mortero y por lo tanto absolutamente compatible. No obstante, a pesar de estos resultados positivos consideramos la necesidad de realizar pruebas previas antes de abordar una intervencion general en este tipo de revestimientos, pues tanto el nivel de descohesión de la capa pictórica, así como su posición en vertical (revestimientos in situ), pueden influir en la respuesta al tratamiento. Además su reciente incorporación en el campo de los revestimientos polícromos hace que no se puedan conocer todavía los efectos que a largo plazo se pudieran producir.

En conclusión, esta investigación evidencia la necesidad de continuar realizando estudios sobre productos de consolidación, tanto aquellos utilizados de manera tradicional como de otros de reciente incorporación, con el objetivo de ofrecer a los restauradores las herramientas necesarias para seleccionar los tratamientos más adecuados para las obras a tratar. De esta manera, evitaremos comportamientos indeseados que provoquen daños en los materiales, contribuyendo a su conservación.

Además, la metodología aplicada ha demostrado ser efectiva por lo que ha permitido extraer resultados concluyentes y con garantías en esta primera fase de la investigación.

\section{Agradecimientos}

Queremos hacer constar nuestro más profundo agradecimiento al proyecto FORVM MMX, en especial a su director Marcelo Castro, por permitirnos el estudio de estos revestimientos murales, y a $M^{\text {a }}$ de la Paz López, restauradora, por la información que nos ha facilitado, así como al Departamento de Microbiología de la Universidad de Granada, concretamente a la doctora Fadwua Jroundi por proporcionarnos la solución nutritiva de la carbonatogénesis bacteriana. También agradecemos la colaboración de la doctora Isabel Guerra Tshchuschke, quien ha realizado los análisis mediante HRSEM en el Centro de Instrumentación Científica de la Universidad de Granada.

Asimismo, la realización de este trabajo ha sido posible gracias a la financiación por el Ministerio de Economía y Competitividad y por el Fondo Europeo de Desarrollo Regional(FEDER) en el marco del Proyecto de Investigación Estudio científico y tratamientos de conservación en revestimientos arquitectónicos de época romana a medieval, de referencia (HAR2015-66139-P), al proyecto Decoración arquitectónica de tradición islámica. Materiales y técnicas de ejecución, de referencia (HAR 2011- 27598) $(01 / 01 / 2012$ - 31/12/2015) y al proyecto de excelencia de la Junta de Andalucía Tratamientos cromáticos en la arquitectura de tradición Hispanomusulmana. Técnica y Conservación (HUM 1941) (01/01/2014 - 31/12/2017). Ha sido posible gracias a la obtención de la beca de Formación del Profesorado Universitario (FPU) de Teresa López Martínez, y del programa de contratos puentes de la Universidad de Granada, del cual Ana Isabel Calero Castillo ha sido beneficiaria. Finalmente, este artículo se ha realizado dentro del programa de Doctorado de Historia y Artes de la Universidad de Granada

\section{Bibliografía}

AA.VV. (2003): Criterios de intervención en materiales pétreos. Revista Bienes Culturales del Instituto de Patrimonio Histórico Español, (2).

BRANDA, S., VIK A., FRIEDMAN, L., KOLTER, R. (2005). Biofilms: The matrix revisited. Trends Microbiol, 13, 20-26.

BOQUET, E., BORONAT, A., RAMOS-CORMENZA, A. (1973). Production of calcite (calcium carbonate) crystals by soil bacteria is a general phenomenon. Nature, 246, 527-529.

DAL MONTE, R. (1998). Morteros de consolidación para revestimientos pintados. La línea PLM. Un nuevo silicato de etilo para pintura mural: Bioestel. En J. Barberó Encinas, Técnicas de consolidación en pintura mural. Actas del Seminario Internacional sobre la Consolidación de pintura mural celebrado en Aguilar del Campoo (Palencia) (págs. 75-95). Aguilar del Campoo (Palencia): Fundación Santa María la Real. Centro de estudios del románico. 
GONZÁLEZ-MUÑOZ, M. T., JROUNDI, F., GARCÍA BUENO, A., MARTÍN PEINADO, B., \& RODRÍGUEZ-NAVARRO, C. (2015). Bioconsolidación de materiales pétreos y ornamentales mediante carbonatogénesis bacteriana. La ciencia y el arte $\mathrm{V}$. Ciencias experimentales y conservación del patrimonio, (págs. 71$80)$.

GONZÁLEZ-MUÑOZ, M. T., RODRÍGUEZ-NAVARRO, C.; JIMÉNEZLÓPEZ, C., RODRÍGUEZ-GALLEGO, M. (2008). Método y producto para la protección y consolidación de materiales de construcción y ornamentales. Patente WO 2008/009771 A1.

GUASCH FERRÉ, N. (2009). Caracterització dels materials constitutius de les bases de preparació de les pintures murals a les terres baixes maies del nord (Península de Yucatán, Méxic), Universitat Politècnica de València.

GUIRAL PELEGRíN, C., \& MARTíN-BUENO, M. (1996). Bílbilis I. Decoración pictórica y estucos ornamentales. . Zaragoza: Institución Fernando el Católico.

JROUNDI, F., FERNÁNDEZ-VIVAS, A., RODRIGUEZ-NAVARRO, C., J. BEDMAR, E., GONZÁLEZ-MUÑOZ, M.T. (2010). Bioconservation of deteriorated monumental calcarenite stone and identification of bacteria with carbonatogenic activity. Microbial Ecology, 60, 39-54.

JROUNDI, F., GONZÁLEZ-MUÑOZ, M. T., GARCIA BUENO, A., \& RODRÍGUEZ-NAVARRO, C. (2014). Consolidation of archeological gipsum plaster by bacterial biomineralization of calcium carbonate. Acta Biomaterialia, 10, 3844-3854.
JROUNDI, F., RODRÍGUEZ-NAVARRO, C., GARCÍA BUENO, A., MEDINA- FLÓREZ, V., \& GONZÁLEZ-MUÑOZ, M. T. (2011). Consolidación de materiales arqueológicos procedentes del Alcázar de Guadalajara, mediante carbonatogénesis bacteriana. XVIII Congreso Internacional Conservación y Restauración en Bienes Culturales (págs. 125-127). Granada: Universidad de Granada.

LÓPEZ MARTÍNEZ, T., LÓPEZ CRUZ, O., GARCÍA BUENO, A., CALERO-CASTILLO, A.I., \& MEDINA FLÓREZ, V. (2016). Las pinturas murales de Castulo. Primeras aportaciones a la caracterización de materiales y técnicas de ejecución. Lucentum, (35), en prensa.

LÓPEZ ORTEGA, T. (1999). Evaluación de los tratamientos de conservación efectuados en los mascarones de estuco de Kohunlich. Mexico. Distrito Federal: Quintana Roo.

MORA, P., MORA, L., \& PHILIPPOT, P. (2001). La conservazione delle pitture murali. (Segunda ed.). Bologna: Editrice compositori.

MORENO CIFUENTES, M.A. (1998). La consolidación de revestimientos murales en yacimientos arqueológicos. En J. Barberó Encinas, Técnicas de consolidación en pintura mural. Actas del Seminario Internacional sobre la Consolidación de pintura mural celebrado en Aguilar del Campoo (Palencia) (págs. 53-75). Aguilar del Campoo (Palencia): Fundación Santa María la Real. Centro de estudios del románico.

RODRIGUEZ NAVARRO, C., JROUNDI, F., GONZÁLEZ-MUÑOZ, M.T. (2015). Stone consolidation by bacterial carbonatogenesis: Evaluation of in situ applications. Restoration of Buildings and Monuments, 21 (1), 9-20.

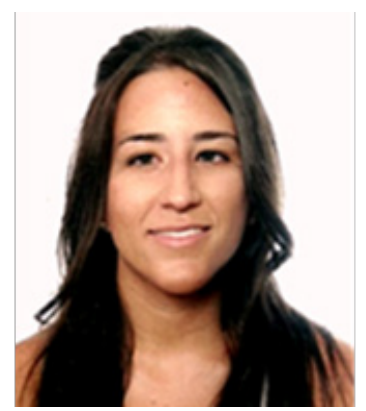

\author{
Ana Isabel Calero Castillo \\ anacalerocastillo@hotmail.com \\ Universidad de Granada
}

Doctora en Artes, especialidad Técnicas de Restauración y conservación de obras de arte con mención europea en el año 2016. Actualmente es miembro del Departamento de Pintura de la UGR con un contrato puente del plan propio de la misma universidad. Ha sido becaria FPU y miembro investigador en diversos proyectos competitivos de I+D orientados a la recuperación del color en la arquitectura y al estudio de los revestimientos cromáticos. Ha trabajado en diversos proyectos de restauración como el estudio de las yeserías del patio de las Doncellas del Real Alcázar de Sevilla y el de las pinturas murales de Castulo. Ha realizado además dos estancias formativas en Roma (Italia) en los laboratorios de restauración de pintura mural del ISCR, lo que le ha permitido trabajar en la restauración de revestimientos murales de Pompeya, el ciclo pictórico de Sant'Agata que se encuentra en Largo dei mutilati ed invalidi da guerra así como en las estancias de Piranesi de época romana situadas en Villa Massenzio en el Appia Antica entre otras. 


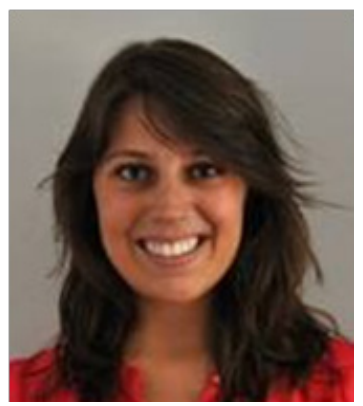

\title{
Teresa López Martínez
}

terelm@ono.com

Universidad de Granada

Graduada en Conservación y Restauración de Bienes Culturales por la Universidad de Granada en el año 2014. Es miembro del Departamento de Pintura de la Universidad de Granada gracias a la beca de Formación del Profesorado Universitario (FPU) de la que disfruta desde el año 2015 y gracias a la cual actualmente está realizando su tesis doctoral. Ha participado en diversos proyectos en Italia durante su beca Erasmus como los estudios previos de la sala II ridotto del Teatro Grande o del monumento a Arnaldo, ambos en Brescia, así como en diversas restauraciones, entre las que destacan la Madonna Nera de la iglesia de Santa Maria della Caritá o la escultura pétrea II Bigio. Además ha realizado prácticas de arqueología en el Alfar de Cartuja (Granada) así como en Castulo. Ha colaborado en el desarrollo de proyectos I+D orientados al estudio de revestimientos cromáticos. Fruto de ese trabajo se han realizado diversas aportaciones a congresos y publicaciones en revistas nacionales.

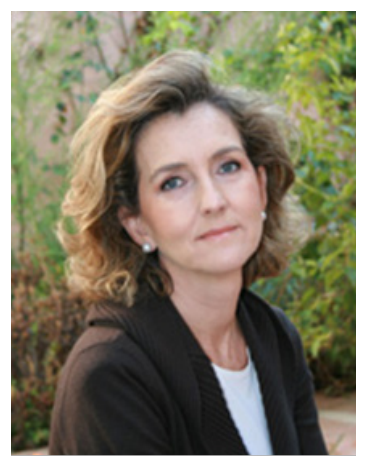

\author{
Ana García Bueno \\ anagar@ugr.es \\ Universidad de Granada
}

Profesora Titular del Departamento de Pintura, especialidad de Restauración, actualmente directora del Departamento de Pintura de la UGR. Ha sido miembro investigador en diversos proyectos competitivos de I+D orientados a la recuperación del color en la arquitectura y al estudio de los revestimientos cromáticos, sobre todo en la Arquitectura Islámica. En relación con su actividad profesional, ha participado en diversos proyectos de restauración de pintura mural, entre los que destacan los trabajos llevados a cabo en Qsayr 'Amra (Jordania), miembro integrante del asesoramiento facultativo durante la intervención en los elementos decorativos del Cuarto Real de Santo Domingo; los estudios previos de la Madraza y de varios espacios del Real Alcázar de Sevilla como la fachada del palacio de Pedro I o la decoración arquitectónica del patio de las Doncellas, así como los revestimientos romanos de Cástulo. Fruto de estas investigaciones se han publicado numerosos artículos s en revistas indexadas y ha dirigido varias tesis doctorales. 


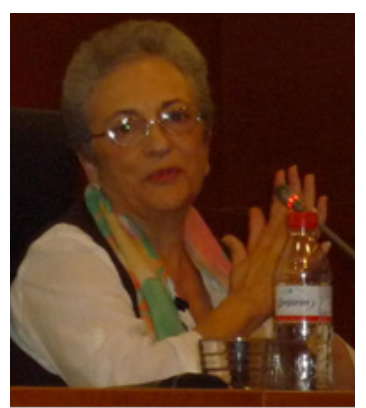

\title{
María Teresa González Muñoz
}

mgonzale@ugr.es

Universidad de Granada

Catedrática de Microbiología, actualmente es Profesora Emérita de la Universidad de Granada. Con dilatada labor docente (en Licenciatura, Grado, Doctorado y Máster) y amplia tarea investigadora en diferentes campos de la Microbiología. Ha desarrollado, en los últimos 25 años, una línea de investigación interdisciplinar con profesores e investigadores (de Universidad y del CSIC) del Área de Mineralogía y Cristalografía sobre diferentes aspectos de la Biomineralización bacteriana, con importantes aportaciones plasmadas en numerosas publicaciones de elevado índice de impacto, habiendo desarrollado una patente de un producto y método para consolidación de materiales de construcción y ornamentales, licitada ya por una empresa. Investigadora e I. P. de numerosos Proyectos de Investigación, destaca, además, su colaboración de los últimos años con profesores e investigadores de Belllas Artes y Arquitectura.

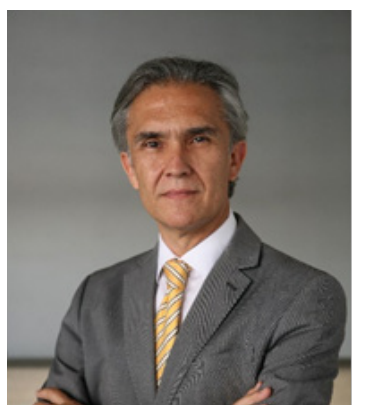

\section{Victor J. Medina Flórez}

vmedina@ugr.es

Universidad de Granada

Catedrático del Departamento de Pintura, de la Facultad de Bellas Artes desde el año 2008 y en la actualidad Vicerrector de Extensión Universitaria de la UGR. Desde su incorporación en la misma universidad en 1997, su docencia e investigación se han relacionado con temas de Conservación y Restauración, fundamentalmente restauración de pintura mural y conservación preventiva. Ha sido investigador en diversos proyectos competitivos de I+D orientados a la recuperación del color en la arquitectura y al estudio de los revestimientos cromáticos. Como resultado de este trabajo ha dirigido varias tesis doctorales y realizado más de 40 publicaciones especializadas. Ha participado en diversos proyectos de restauración como son el de los revestimientos murales de Luca Jordan, Carreño y Rizzi, Qsayr 'Amra (Jordania), la Casa de Zafra, el Corral del Carbón; los estudios previos de la Madraza, los Reales Alcázares de Sevilla, o las pinturas arqueológicas de época romana de Cástulo, además de otras obras.

\author{
Artículo enviado el 04/02/2016 \\ Artículo aceptado el 21/09/2016
}

